\title{
BENS IRREDUTIVELMENTE SOCIAIS COMO PRESSUPOSTO PARA A DEFESA DE DIREITOS COLETIVOS
}

\author{
Inácio Helfer ${ }^{1}$ \\ Universidade do Vale do Rio dos Sinos (UNISINOS) \\ Universidade de Santa Cruz do Sul (UNISC) \\ (iD) https://orcid.org/0000-0001-6809-9009 \\ E-mail: inahelfer@gmail.com \\ Odair Camati ${ }^{2}$ \\ Universidade de Caxias do Sul (UCS) \\ https://orcid.org/0000-0002-8637-3072 \\ E-mail: odcamati@hotmail.com
}

\section{RESUMO:}

O presente estudo analisa o conceito tayloriano de bens irredutivelmente sociais. Além disso, visa avaliar a possibilidade da existência de bens intrinsecamente sociais, ou se todos os bens, em última análise, devem ser compreendidos apenas como bens originariamente formulados enquanto bens individuais. Caso existam bens intrinsecamente sociais, que consequências podem ser derivadas no que tange à discussão em torno dos direitos coletivos? $\mathrm{O}$ tratamento destas questões é levado à cabo no artigo Bens irredutivelmente sociais, de Charles Taylor, onde o filósofo canadense afirma que existem bens convergentes e bens irredutivelmente sociais. Os convergentes seriam aqueles que podem ser decompostos em bens individuais, ou seja, são aqueles que somente indivíduos podem acessar; por outro lado, bens irredutivelmente sociais são aqueles partilhados por um grupo humano ou que possuam um significado comum concedido por um pano de fundo, o que impede que sejam decompostos primariamente em bens individuais. Após essa análise, nos propomos a apresentar as consequências teóricas que podem ser derivadas da defesa de bens sociais.

PALAVRAS-CHAVE. Bens irredutivelmente sociais; Bens convergentes; Direitos coletivos; Charles Taylor.

\section{IRREDUCIBLY SOCIAL GOODS AS A PRESUPPOSITION FOR THE DEFENSE OF COLLECTIVE RIGHTS}

\begin{abstract}
:
The present study analyses the taylorian concept of irreducibly social goods. Besides that, aims to evaluate the possibity of existence of intrinsically social goods, or if all the goods, ultimately, shoud be understood only as goods originally formulated as individual goods. If there are intrinsically social goods, what consequence does this point of view have for the treatment of collective rights? The treatment of these questions is carried out by Taylor's article Irreducibly Social Goods, where the Canadian philosopher states that there are convergent goods and irreducibly social goods. Convergent goods would be those that can be broken down into individual goods, that is, those that only individual can access; on the other hand irreducibly social goods are those shared by a human group or having a common meaning given by a background, this goods have not be broken down into individual goods. Finally, the study aims to present the consequences of this discussion in relation to the concept of collective rights.
\end{abstract}

KEYWORDS: Irreducibly social goods; Converging good; Collective rights; Charles Taylor.

\footnotetext{
${ }^{1}$ Doutor em Filosofia pela Université de Paris 1/Panthéon-Sorbonne. Professor titular da Universidade do Vale do Rio dos Sinos (UNISINOS), São Leopoldo - RS, Brasil e da Universidade de Santa Cruz do Sul (UNISC), Santa Cruz do Sul - RS, Brasil.

2 Doutor em Filosofia pela Universidade do Vale do Rio dos Sinos (UNISINOS), São Leopoldo - RS, Brasil. Realiza estágio pós-doutoral na Universidade de Caxias do Sul (UCS), Caxias do Sul - RS, Brasil.
}

HELFER, Inácio; CAMATI, Odair. Bens irredutivelmente sociais como pressuposto para a defesa de direitos coletivos. Griot : Revista de Filosofia, Amargosa - BA, v.19, n.1, p.174-185, fevereiro, 2019. 


\section{Introdução}

Existem bens irredutivelmente sociais ou apenas bens individuais? Esse é o questionamento que nos guiará nesse texto. Aliás, tal questionamento está subjacente em todo pensamento político do pensador canadense Charles Taylor, mas em especial no artigo Bens irredutivelmente sociais. Quando afirmamos que está subjacente em todo pensamento político do filósofo nos direcionamos mais especificamente à discussão em torno do multiculturalismo e da possibilidade de construção de direitos coletivos. Nesse sentido, o que queremos explicitar é a estreita ligação entre bens sociais ou comuns e a possibilidade de direitos coletivos.

Fundamental nessa discussão é o conceito de identidade dialógica. É importante ressaltar que a presente discussão tem por objetivo apresentar argumentos que se contraponham ao atomismo. Nesse sentido, a dialogicidade da identidade configura-se como um primeiro argumento contrário ao atomismo, pois nosso aspecto mais fundamental, a identidade, só pode ser construída no diálogo com o outro. $O$ outro entendido aqui como as pessoas que nos são mais próximas, a comunidade que fazemos parte e também a sociedade como um todo.

A tese tayloriana é que nossa identidade está fortemente atrelada ao reconhecimento ou sua ausência. $\mathrm{O}$ não-reconhecimento pode causar graves danos à identidade de um indivíduo ou de um grupo de indivíduos. Como exemplos clássicos temos o caso dos negros e das mulheres que durante séculos foram vistos como inferiores em nossa sociedade e quando foram reconhecidos como iguais tiveram e ainda têm dificuldades para ocuparem efetivamente os seus espaços. (TAYLOR, 2000). Esse fenômeno acontece, pois indivíduos ou grupo de indivíduos não reconhecidos acabam como que introjetando uma visão depreciativa de si mesmos. Para superar esse momento é preciso que indivíduos ou grupos de indivíduos não reconhecidos expurguem a visão distorcida que possuem de si mesmos e passem a ocupar seus espaços.

Falamos em indivíduos ou grupo de indivíduos, pois podemos tratar do reconhecimento em dois âmbitos: público e privado. $O$ reconhecimento no âmbito privado não inspira maiores questionamentos, nos parece evidente a necessidade que possuímos do reconhecimento de nossos pares mais próximos. As dificuldades surgem quando tratamos do reconhecimento em âmbito público, ou seja, o reconhecimento de grupos de indivíduos, ou se quisermos de culturas. Em alguns casos coloca-se a necessidade de uma defesa de direitos coletivos no intuito de garantir a sobrevivência e o consequente reconhecimento de minorias culturais socialmente fragilizadas.

Há uma discussão intensa na filosofia política contemporânea ${ }^{3}$ sobre a existência ou não de direitos coletivos. Numa tentativa de esquivar-se dessa discussão, Will Kymlicka, apresenta uma nova possibilidade de conceituação, ao utilizar a seguinte expressão: “direitos diferenciados em função de grupo", o que, em nosso entendimento, não dissolve o problema, pois para que existam tais direitos é necessário que se reconheçam grupos como portadores dos mesmos. Nosso intuito não é o de resolver plenamente o problema, mas apenas apresentar o conceito de bens

\footnotetext{
3 A seguir apresentamos alguns textos que são referência no que estamos discutindo. Cf. KYMLICKA, Ciudadanía Multicultural; SANTOS, Uma concepção multicultural de direitos humanos; WALZER, Esferas de justiça. .
} 
irredutivelmente sociais a partir de Charles Taylor como um argumento em favor da adoção de direitos coletivos. Se existem bens sociais, somente uma comunidade cultural enquanto tal poderá usufruí-los e, para que isso ocorra, é necessário que a estrutura básica de tal cultura esteja salvaguardada.

\section{Bens convergentes e bens irredutivelmente sociais}

Retomamos mais de perto o questionamento que nos colocamos no início do presente artigo. Existem bens sociais ou podemos decompô-los em bens individuais? A tradição ocidental liberal tem afirmado que todos os direitos podem ser decompostos em direitos individuais, pois o único sujeito que deles pode usufruir é o próprio indivíduo. Essa concepção é decorrente da tradição contratualista e do utilitarismo em sua vertente atomista. Surpreendentemente, Charles Taylor ao desenvolver essa questão apresenta apenas o utilitarismo em sua vertente atomista como o precursor da ideia de que apenas indivíduos podem acessar direitos. Em nosso entendimento não podemos deixar de tratar da tradição contratualista como precursora do individualismo metodológico. Em outros textos ${ }^{4}$ o pensador canadense desenvolve essa temática, o que justifica nosso estranhamento com relação ao artigo Bens irredutivelmente sociais.

Como não é nosso objetivo apresentar as razões do porquê Taylor não considera também o contratualismo iremos adiante a fim de analisarmos os argumentos atomistas do utilitarismo. Segundo Taylor, são três os pressupostos filosóficos presentes no utilitarismo. ${ }^{5}$ Não vamos problematizar tais pressupostos, iremos apresentá-los no intuito de verificar se os argumentos taylorianos oferecem respostas satisfatórias. O primeiro pressuposto do utilitarismo é o que, podemos chamar, de consequencialismo, tendo em vista que o mais importante são os resultados de uma ação. Portanto, o valor moral é determinado pelas consequências de uma determinada ação. $O$ segundo pressuposto é utilitário, ou seja, os "estados de coisas" ou os resultados de uma ação devem ser avaliados pela maximização da felicidade e da satisfação dos agentes. $O$ terceiro e, mais importante para nossa discussão, é o atomismo, já que a utilidade deve ser analisada a partir da satisfação de indivíduos. ${ }^{6}$ Diante desses pressupostos, parece evidente que bens são sempre e necessariamente bens individuais, pois no fundo apenas indivíduos ficam satisfeitos (ou não) com o curso de uma determinada ação.

Nessa linha de raciocínio, mesmo que não se possa identificar quem são os indivíduos beneficiados, sempre é possível decompor os bens em nível individual. Não negamos que determinados bens possam ser decompostos e a esses bens chamamos de convergentes. Contudo não é possível afirmar que todos os bens sejam apenas convergentes. Vamos analisar mais de perto o argumento atomista:

\footnotetext{
4 Apresentamos aqui alguns textos em que Taylor desenvolve a temática do atomismo. Cf. TAYLOR, Argumentos filosóficos; TAYLOR, A ética da autenticidade.

${ }^{5}$ Entendemos que a apresentação tayloriana do utilitarismo é insuficiente. Não problematizaremos com maior atenção esse ponto, porque não seria possível fazê-lo sem que isso levasse a discussões periféricas, portanto, não fundamentais, tendo em vista o objetivo que nos colocamos no início do texto.

${ }^{6}$ Esse argumento é desconstruído por Rawls, em Uma teoria da justiça. Para Rawls, o utilitarismo não leva a sério a distinção entre pessoas, portanto, não pode ser afirmado como uma teoria individualista. Essa lembrança serve para alertar que esse é um argumento controverso.
} 
Pensar que a sociedade consiste em alguma outra coisa, acima e além dessas escolhas e ações individuais, é invocar alguma entidade estranha e mística, um espírito espectral de coletividade, com que nenhuma ciência sóbria e respeitável quer ter algo a ver. É vagar nas névoas hegelianas em que todos os viajores têm de terminar perdidos para sempre para a razão e a ciência. (TAYLOR, 2000, p. 145).

Tudo isso faz com que o atomismo pareça evidente e que não haveria qualquer outra forma de organização social que não aquela baseada exclusivamente em bens individuais. Quando analisamos mais profundamente o funcionamento da sociedade percebemos que existem papéis, cargos, leis e status que permeiam uma organização social, mas que no fim são ocupados por indivíduos. Na base dessas diferenciações estão pensamentos e ações que só podem ser desenvolvidas por indivíduos.

Entretanto, todos esses argumentos parecem insuficientes para justificar o atomismo, pois se na base de todas as ações humanas estão os pensamentos não é possível afirmar que o atomismo esteja justificado. Pensamentos só podem existir em uma rede de significados que não pode ser definida aleatoriamente por indivíduos isolados, mas sim por uma comunidade linguística formadora de um pano de fundo que permite aos pensamentos adquirem significados, e que posteriormente serão utilizados por indivíduos. Nesse sentido, o uso é individual, mas seu significado é fornecido por um pano de fundo transcendente aos indivíduos.

\footnotetext{
Nesse contexto, Taylor invoca o segundo Wittgenstein, o qual representa a figura central da filosofia contemporânea que alterou significativamente a compreensão que se tinha acerca do pensamento e da linguagem. Com a utilização da imagem do jogo, sua contribuição teria sido decisiva para entender a atividade humana regida por regras, em que surgem questões de validade e de não-validade. (HELFER, 2012, p. 7).
}

As coisas ou ações só possuem significado no interior de um pano de fundo. Por exemplo, em sociedades primitivas falar em "sofisticado" não fazia nenhum sentido, pois não estava presente naquela linguagem esse vocábulo e obviamente não havia significado semântico para esse termo. No sentido apresentado por Wittgenstein, não fazia parte das regras de linguagem daquelas sociedades a existência e o uso do termo "sofisticado".

Nesse sentido, uma linguagem é constituída e transformada por uma comunidade linguística nos intercâmbios contínuos que existem em seu interior. Isso significa que nenhuma linguagem é estática, pois pode ser transformada e reconstruída, mas requer sempre um pano de fundo capaz de atribuir significado às mudanças em percurso. Os indivíduos podem contribuir nessa transformação desde que se coloquem em relação direta com o pano de fundo da comunidade na qual pertencem. Há uma relação direta dessa concepção de linguagem mais aberta com a formação da identidade humana, a esse elemento Semprini chama de "teoria intersubjetiva do sujeito":

Ao contrário, uma teoria intersubjetiva do indivíduo procura reconhecer a importância das noções de enraizamento na construção do eu. Neste sistema, a identidade individual é concebida como uma estrutura oca, que 
toma forma somente no quotidiano do processo de educação e aprendizagem. Isto fornece ao indivíduo um sistema de valores e de normas de conduta, permitindo-lhe 'compreender' o mundo e sua posição no interior deste. (SEMPRINI, 1999, p. 102).

Da mesma forma que o pano de fundo confere significado às nossas palavras, uma cultura fornece significado às nossas ações. Essa analogia é importante para que possamos nos contrapor ao atomismo, demonstrando que desde aquilo que pensamos até aquilo que realizamos, só o fazemos porque existe um pano de fundo por trás que confere significado, sem o qual estaríamos como que "submergidos" em um mundo sem significado.

A argumentação tayloriana nos permite afirmar que até mesmo a existência de alguns pensamentos não seria possível sem a existência de um pano de fundo fornecido por uma comunidade linguística. Como já dissemos, em comunidades primitivas não era possível pensar em uma pessoa ou em um local como sofisticado, uma vez que não existiam significados para esse termo.

Nessa perspectiva, há uma diferença crucial entre "eventos puros e simples"e "eventos de significado", o que nos permite uma melhor compreensão do argumento tayloriano. Um evento puro e simples é o que não requer um pano de fundo para que se possa compreendê-lo, em outras palavras, não exige uma explicitação através da linguagem. Por exemplo, uma comunidade neolítica não poderia construir uma pirâmide, haja vista, que não possuía o contingente necessário de escravos para tal. Essa é uma conclusão advinda da observação. Por outro lado, tal comunidade não poderia utilizar o termo "sofisticado", pois esse não fazia parte do pano de fundo dessa comunidade ou do sistema linguístico presente nessa mesma comunidade. Segundo Taylor, o grande erro de Hobbes, Locke e Condillac (TAYLOR, 2000, p. 149) no que tange à linguagem foi esquecer que nem todos os eventos são puros e simples, pois podemos falar também em eventos de significado que não podem ser analisados isolados de seu pano de fundo.

Portanto, eventos de significado só existem em relação a um pano de fundo. Nessa esteira argumentativa Taylor apresenta a diferença saussuriana entre langue e parole.

Existe um código (langue), código a que se recorre em cada ato de fala particular (parole). Estes mantêm entre si uma relação circular característica. Os atos de parole pressupõem, todos eles, a existência da langue, mas esta é constantemente recriada neles. (TAYLOR, 2000, p.151).

Não há a possibilidade do atomismo na linguagem, pois a langue é uma prática normativa da comunidade, ou em outras palavras, um indivíduo isoladamente não pode criar ou aprimorar uma langue. É óbvio que, na interação entre indivíduos, a parole poderá vir a transformar em algum grau a langue, mas novamente existe a necessidade de uma troca no interior de uma comunidade linguística, na qual a langue serve como parâmetro avaliativo. $O$ argumento atomista consiste em afirmar que são indivíduos que fazem uso da parole, desse modo, poderíamos decompor a linguagem em escala individual, o que não se sustenta, pois indivíduos só podem utilizar a parole na relação com uma langue. 
Como sustenta Taylor, embasado em Saussure, a langue "não é uma matéria individual, mas a prática normativa de uma comunidade." (TAYLOR, 2000, p. 150).

Taylor apresenta a discussão em torno da linguagem para afirmar que as características importantes da vida social como papéis, leis, cargos e status existem no pensamento e na linguagem humana, consequentemente só podem existir na relação com um pano de fundo que lhe atribua significado. "Cada indivíduo que cumpre um papel é um ato de parole que pressupõe uma langue de base". (TAYLOR, 2000 , p. 151). A argumentação saussuriana se aplica tanto à linguagem quanto à organização social, na qual somos indivíduos que agem a partir de um campo de significado mais amplo que atribui sentido às nossas ações.

O lócus de ação individual é a sociedade. Seguindo a argumentação saussuriana podemos afirmar que a langue é a cultura, visto que nos fornece os elementos valorativos para analisarmos nossas ações. Só podemos julgar algo como bom, como valioso, ou como importante se estivermos em relação direta com um pano de fundo cultural. A isso Taylor chama também de configurações morais, como nos lembra Araujo:

\footnotetext{
A busca do bem é o que dá o caráter moral às nossas ações; portanto, o que está em jogo para o pensamento de Taylor é como se guiar para realizar o bem a partir de pressuposições básicas de valores, que se caracterizam como aquilo que Taylor intitulou de 'Configurações'. São elas que possibilitam o contexto em que nossas ações e reações morais ganham um significado específico, além de constituírem um modo de orientação essencial à nossa identidade. (ARAUJO, 2004, p. 162).
}

A cultura constitui, portanto, o pano de fundo onde os indivíduos podem guiar suas decisões. No interior de uma cultura existem bens avaliados de acordo com os elementos que são valorados pelos indivíduos e pela comunidade humana, mas não é possível afirmar que exista um bem de origem estritamente individual, visto que o bem só adquire significado na interação entre os indivíduos. Nessa esteira, é possível afirmar a cultura como um bem público, pois somente continuará a existir através de uma garantia fornecida por um grupo de indivíduos que compreende suas vivências culturais como valiosas.

A presente argumentação está fortemente atrelada ao entendimento tayloriano de moralidade, entendida não apenas como o que devemos fazer, mas o que é bom ser. Nessa esteira, a moral precisa dar conta de questões relacionadas ao que constitui uma vida boa. Com esse objetivo em mente, a moral, para Taylor, está vinculada às configurações morais circundantes aos indivíduos que devem tomar decisões.

\footnotetext{
O que venho chamando de configuração incorpora um conjunto crucial de distinções qualitativas. Pensar, sentir, julgar no âmbito de tal configuração é funcionar com a sensação de que alguma ação ou modo de vida ou modo de sentir é incomparavelmente superior aos outros que estão mais imediatamente ao nosso alcance. (TAYLOR, 2011b, p. 35).
}

Os elementos, acima expostos, logram, em nosso entendimento, enfraquecer o atomismo, na medida em que, conectam nossa identidade e nossas decisões morais ao 
espaço cultural que vivenciamos. Entretanto, isso ainda não é suficiente para afirmarmos que os elementos presentes nas diferentes configurações morais devem ser afirmados como importantes e, por isso, estarem sob proteção coletiva. Se assim o fosse, todas as demandas coletivas, por si mesmas, deveriam ser afirmadas enquanto valiosas. Falta no pensamento tayloriano algum elemento que possa nos auxiliar a classificar quais demandas coletivas devem ser atendidas e quais devem ser repensadas.

Se quisermos usar de termos rawlsianos, há em Taylor uma soberania do bem sobre o justo. Os problemas decorrentes dessa concepção nos são conhecidos, pois não há um critério que permita avaliar diferentes concepções de bem, sejam individuais ou coletivas. Em As fontes do self, o pensador canadense nos oferece apontamentos para dar conta dessa problemática. Trata-se da busca por hiperbens presentes nas comunidades humanas. Os hiperbens funcionariam como termômetro para avaliar todos os demais bens e verificar sua plausibilidade. Podemos ainda questionar como devemos discernir quais serão os hiperbens. Taylor nos responde:

O raciocínio prático (...) é um raciocínio em termos de transições. Ele visa estabelecer não que alguma posição seja absolutamente correta, mas que alguma posição é superior a outra. (...) A argumentação fixa-se na natureza da transição de A para B. O cerne da prova racional consiste em demonstrar que essa transição produz uma redução de erros. (TAYLOR, 2011 b, p. 101).

Portanto, segundo Taylor, podemos afirmar alguns bens como mais determinantes do que outros simplesmente através do raciocínio em transição. É possível afirmar, em linhas gerais, que esse argumento é decorrente do comunitarismo presente em Taylor, o que o impede de apresentar critérios formais ou procedimentais. Com isso, podemos retomar mais diretamente a discussão sobre bens sociais e bens convergentes, pois até o momento analisamos o confronto e refutação dos argumentos atomistas desenvolvida por Taylor que nada mais é do que a fundamentação para a ideia de bens irredutivelmente sociais.

Uma primeira maneira de identificarmos bens sociais é analisarmos sua instrumentalidade. Por exemplo, uma represa não pode ser considerada um bem intrinsecamente social, pois tem um papel instrumental, como por exemplo, salvar $\mathrm{X}$ casas de uma inundação. A represa em si não é um bem, antes é o resultado da implantação de uma represa que se constitui como um bem. Nesse sentido, os efeitos da represa podem ser decompostos: salva a casa $A$, a casa $B$ e assim por diante. Ao contrário, por exemplo, de afirmarmos que determinada forma de heroísmo é boa, esse é um bem que não pode ser instrumentalizado, pois só poderá existir um indivíduo herói se assim a comunidade cultural o julgar. Ou seja, os critérios de julgamento são apresentados por um grupo cultural que transcende o indivíduo, e se são considerados valiosos, não são utilizados, simplesmente, de forma instrumental pelos indivíduos.

Taylor apresenta ainda os exemplos da franqueza e da igualdade, valores morais que só possuem validade em uma sociedade que os considera importantes. Numa sociedade hierárquica, por exemplo, a igualdade nada representa, pois não faz parte de seu pano de fundo colocar a igualdade como um valor, o que deve acontecer 
apenas é que sejam respeitadas as hierarquias sociais e que cada um seja tratado de acordo com o posto que ocupe. Portanto, cada cultura possui uma estrutura própria de valoração que, como dissemos, transcende o indivíduo, mas que ao mesmo tempo pode ser modificada pela ação do indivíduo, desde que as mudanças também estejam diretamente relacionadas com o pano de fundo cultural.

Esse é um primeiro argumento em favor de bens sociais, ou seja, são aqueles que estão diretamente ligados a uma cultura e que não podem ser valorados fora desse contexto. Aos primeiros podemos chamar de bens culturais. $O$ segundo argumento diz respeito àqueles bens que necessitam de uma compreensão e de uma vivência comum. "Uma coisa é comum quando existe não só para mim e para você mas para nós, sendo reconhecida como tal." (TAYLOR, 200, 155). Dois exemplos são apresentados pelo filósofo canadense para ilustrar esse argumento. Ele se pergunta, neste sentido, o que seria do amor e da amizade se não houvesse uma compreensão e uma vivência comum desses sentimentos? Não é possível viver a amizade de maneira atomista, é preciso que esse sentimento seja partilhado por outro que me percebe como seu amigo. ${ }^{7}$ Numa relação de amizade existem ao menos duas compreensões básicas: primeiro deve haver uma compreensão mútua entre os indivíduos que partilham de uma amizade e segundo deve haver a compreensão de que a amizade é algo valioso e deve ser cuidada. Sobre esse ponto afirma Abbey:

O que a frase ‘bens irredutivelmente sociais' captura é a categoria de bens
que não podem ser repartidos ou decompostos em bens individuais, mas
que devem ser partilhados por dois ou mais indivíduos - daí sua descrição
como irredutivelmente social. Esses bens são, até um nível, bens para
indivíduos, coisas que eles experimentam e desfrutam. No entanto, Taylor
argumenta que é um erro de categoria pensar nesses bens como apenas
bens individuais. Eles são, ao mesmo tempo, bens para indivíduos e bens
que somente podem ser gerados em comum com outros. ${ }^{8}$ (ABBEY, 2000 ,
p. 118-119).

Quando esteve na Unisinos em 20139, Taylor apresentou também o exemplo da solidariedade. Ele se indagava: como é possível ser solidário de maneira unilateral? A solidariedade exige que o indivíduo seja solidário para com alguém, nesse sentido, é impossível falar de solidariedade atomisticamente. Dessa forma, um bem social é irredutível quando não pode ser compreendido apenas por um indivíduo isoladamente, mas exige uma compreensão comum. Do contrário, nem poderia ser considerado como um bem.

Portanto, existem duas formas de bens sociais, resumidos por Taylor da seguinte maneira: "(1) Os bens de uma cultura que torna concebíveis ações, sentimentos, modos de vida valorizados, e (2) bens que incorporam essencialmente compreensões comuns de seu valor." (TAYLOR, 2000, p. 155). Isso não quer dizer que não exista um contínuo intercâmbio entre essas duas formas de bens sociais. Um

\footnotetext{
${ }^{7}$ Importante notar que nem todos os bens irredutivelmente sociais nos levam a afirmação de direitos coletivos ou políticas públicas. $\mathrm{O}$ caso da amizade e do amor é emblemático, pois não faz sentido exigir qualquer forma de ação comunitária ou estatal que os obrigue, eles são frutos naturais das relações entre indivíduos.

8 Tradução nossa.

9 O debate liberais-comunitários: colóquio com Charles Taylor. Cf. http://www.ihu.unisinos.br/eventos/agenda/321.
} 
bem cultural é valorizado na medida em que obtiver uma compreensão comum, no exemplo que anteriormente apresentamos - a dignidade - podemos afirmar que é um valor cultural na medida em que houver uma compreensão comum na cultura da importância de que todos sejam tratados de forma igualitária.

Taylor apresenta toda essa argumentação para se contrapor ao atomismo e a pretensa neutralidade da teoria bem-estarista. Os bens irredutivelmente sociais colocam em xeque o atomismo, visto que exigem uma compreensão comum e uma vivência comum, no caso, das culturas. Desse modo, nem todos os bens podem ser decompostos e transformados em bens individuais, o que impossibilitaria uma afirmação categórica do atomismo. Além disso, se bens sociais são partilhados, disso não segue a possibilidade de neutralidade, pois como poderá haver neutralidade em bens que são intersubjetivamente partilhados?

\section{Consequências políticas}

A partir do exposto podemos retomar umas das questões que propomos no início desse artigo, a saber, a existência ou não de direitos coletivos. Bens irredutivelmente sociais no interior de uma cultura minoritária com dificuldades de sobrevivência são suficientes para justificar direitos coletivos? Se disso depender a sobrevivência cultural e consequentemente a possibilidade de manutenção de bens sociais, é legítimo que se defendam direitos culturais enquanto direitos coletivos?

Essa discussão perpassa o debate contemporâneo em torno do multiculturalismo. No artigo $A$ política do reconhecimento (2000, p. 241) Taylor se confronta mais diretamente com essa questão ao afirmar que é possível afirmar direitos coletivos e salvaguardar a liberdade individual, pois afirma:

\footnotetext{
É preciso distinguir as liberdades fundamentais, aquelas que nunca podem ser feridas e, portanto, que devem ser incessantemente protegidas de privilégios e imunidades que, embora importantes, podem ser revogadas ou restringidos por razões de política pública - embora se precise de uma forte razão para isso. (TAYLOR, 2000, p. 265).
}

Provavelmente, uma "forte razão" devesse ser entendida como aquela que estivesse diretamente ligada à sobrevivência de determinada cultura ou seu mínimo florescimento. Nesse sentido, pode existir uma sociedade com metas coletivas e, consequentemente, direitos coletivos bem fundamentados somente quando essa sociedade puder salvaguardar a liberdade individual daqueles que não querem seguir tais metas coletivas. Além disso, a sociedade em questão deve criar mecanismos para manter vigentes os direitos fundamentais.

Nesse ponto, podemos pensar sobre o caso do Quebec, província canadense com maioria francofone. É evidente que se o francês for enfraquecido, o será também a cultura presente no Quebec. Na mesma linha de Taylor, compreendemos que a língua é elemento fundamental para a possibilidade da manutenção de uma determinada cultura. Exatamente a partir dessa argumentação é que no Quebec, por exemplo, os filhos de francófonos somente podem frequentar escolas públicas em francês. Claramente temos uma meta coletiva que embasa essa decisão, qual seja, manter a viva a cultura francesa no Quebec. 
Poderíamos perguntar: seria essa prática restritiva à liberdade individual? A resposta é negativa somente na medida em que a sociedade do Quebec aceita que manter a cultura francesa é uma meta valiosa. Existe, nesse sentido, um bem cultural considerado valioso e que exige pequenos sacrifícios por parte dos membros da sociedade. A ressalva apresentada por Taylor é fundamental nessa discussão, a saber, uma meta coletiva considerada como valiosa deve garantir o respeito aos direitos humanos fundamentais. Direitos humanos fundamentais podem ser entendidos aqui, em termos gerais, como os direitos estabelecidos pela Declaração Universal dos Direitos Humanos. ${ }^{10}$

Nessa linha, em nosso entendimento quando um bem cultural for considerado valioso por sua coletividade e não estiver em discordância com direitos fundamentais, está justificada a reivindicação por sua manutenção. Isso significa que a pretensão de absoluta neutralidade liberal não cabe nessa argumentação, somente um Estado "não neutro" é capaz de garantir as condições para a manutenção dos bens culturais valiosos. Isso é ainda mais evidente quando nos referirmos a minorias culturais incapazes de fazer frente às culturas majoritárias. Somente com a garantia estatal tais minorias podem manter vivos seus bens culturais.

Como assinalamos acima essa argumentação encontra um limite, qual seja, como podemos afirmar que algumas demandas coletivas são aceitáveis e outras não o são? Uma possibilidade de resposta, aventada acima, consiste em limitar as demandas tendo como referência os direitos humanos. Mas, se afirmamos a teoria tayloriana como comunitarista e sabendo que nem todas as comunidades humanas aceitam os direitos humanos, ainda poderíamos afirmar que esse é um critério adequado de avaliação?

A partir desse questionamento podemos retomar a ideia, apresentada no ponto anterior, a saber, o raciocínio em transição poderia dirimir possíveis dificuldades de avalição de quais metas coletivas são adequadas e quais não o são, sem a necessidade de recorrermos a um critério formal. Ainda nos parece insuficiente, porque não nos oferece uma garantia de que metas coletivas não venham a restringir direitos individuais. Dentro desse raciocínio, a forma mais adequada de evitar tais problemas é estabelecer um critério de avaliação, o que Taylor não nos apresenta.

Nesse sentido, a teoria tayloriana nos oferece bons elementos para refutar o atomismo e para afirmar a existência de bens irredutivelmente sociais. Contudo, não está suficientemente justificada a necessidade de bens sociais se transformarem em direitos coletivos, ou ao menos, não estão claros os parâmetros para avaliar quais bens serão afirmados como direitos e quais não poderão ser afirmados dessa forma.

\section{Considerações finais}

A partir da tentativa de contraposição ao utilitarismo, especialmente no que diz respeito ao atomismo, Taylor propõe a análise da estrutura da nossa linguagem humana. Tendo embasamento em Wittgenstein e Saussure, o filósofo canadense afirma ser a linguagem um elemento transcendente ao indivíduo, sendo necessário

\footnotetext{
10 Esse não é um ponto de pleno consentimento, porque poderíamos nos perguntar o que são direitos fundamentais e se realmente a Declaração Universal dos Direitos Humanos responde com precisão a esse questionamento. Contudo, para o efeito desse trabalho consideramos a Declaração suficiente.
} 
um pano de fundo doador de sentido para todas as nossas interações linguísticas. Isso significa que o indivíduo precisa do pano de fundo ou de uma langue para compreender aos outros e a si mesmo.

Tendo afirmado a insuficiência do atomismo, passamos a analisar a existência de bens irredutivelmente sociais, ou em outros termos, bens que não podem ser decompostos em bens individuais. É óbvio que existem bens convergentes, tal como uma represa, que em última instância beneficia o indivíduo a, b, c e assim por diante. Mas, existem também bens que não podem ser decompostos dessa maneira. Analisamos com Taylor os bens culturais valorados por uma determinada cultura e os bens sociais. Esses últimos necessitam de uma vivência comum para existirem, como é o caso das relações amorosas e das relações de amizade. Isso nos leva a determinadas consequências políticas, objeto de análise da última seção do presente trabalho.

Portanto, a partir da discussão em torno dos bens irredutivelmente sociais podemos chegar até o debate sobre a existência ou não de direitos coletivos. Partindo da existência de bens sociais no interior de culturas, é de fundamental importância que se criem mecanismos de sobrevivência para essas culturas. $O$ caminho proposto por Taylor é o autogoverno no sentido de que se esbocem metas coletivas a partir dos bens sociais e que ao mesmo tempo se criem mecanismos para salvaguardar direitos fundamentais, especialmente a liberdade. $O$ que ainda precisa de melhor clarificação e que se coloca como limite na teoria tayloriana é: quais os elementos/critérios podem nos garantir que a passagem de bens sociais para direitos coletivos ocorra sem prejuízos à liberdade individual? 


\section{Referências}

ABBEY, Ruth. Charles Taylor. Princeton, Princeton University Press, 2000.

ARAUJO, Paulo Roberto M. Charles Taylor: para uma ética do reconhecimento. São Paulo: Edições Loyola, 2004.

HELFER, Inácio. Os bens sociais são sempre bens convergentes? In.

Trans/Form/Ação v. 35, $\mathbf{n}^{\circ}$ 2, Marília, Maio/Agosto 2012.

KYMLICKA, Will. Ciudadanía multicultural. Una teoría liberal de los derechos de las minorias. Trad. de Carme Castells Auleda. Barcelona: Paidós, 1996.

TAYLOR, Charles. Bens irredutivelmente sociais. In. Argumentos Filosóficos. Trad. de Adail Ubirajara Sobral. São Paulo: Edições Loyola, 2000.

TAYLOR, Charles. A política do reconhecimento. In. Argumentos Filosóficos. Trad. de Adail Ubirajara Sobral. São Paulo: Edições Loyola, 2000.

TAYLOR, Charles. A ética da autenticidade. Trad. de Talyta Carvalho. São Paulo: É realizações, 2011a.

TAYLOR, Charles. As fontes do self. A construção da identidade moderna. Trad. de

Adail Ubirajara Sobral; Dinah de Abreu Azevedo. $3^{\circ}$ Ed. São Paulo: Edições Loyola, $2011 b$.

SANTOS, Boaventura de Souza. Uma concepção multicultural de direitos humanos. Lua Nova, 1997, n. 39, p.105-124.

SEMPRINI, Andrea. Multiculturalismo. Trad. de Laureano Pelegrin. Bauru: EDUSC, 1999.

WALZER, Michael. Esferas de justiça. Uma defesa do pluralismo e da igualdade. Trad. de Jussara Simões. São Paulo: Martins Fontes, 2003.

Contribuição dos autores

Inácio Helfer orientou e revisou os tópicos abordados no artigo. Odair Camati redigiu o texto e desenvolveu pesquisa orientada por Inácio Helfer. A versão final do artigo foi aprovada pelos autores.

Autor(a) para correspondência: Odair Camati, Universidade de Caxias do sul, Rua Francisco Getúlio Vargas, 1130, 95070-560, Caxias do Sul-RS, Brasil. odcamati@hotmail.com 